\title{
Alzheimer's Disease-Like Pathology in Senescence-Accelerated OXYS Rats can be Partially Retarded with Mitochondria-Targeted Antioxidant SkQ1
}

\author{
Natalia A. Stefanova ${ }^{\mathrm{a}, *}$, Natalia A. Muraleva ${ }^{\mathrm{a}}$, Vladimir P. Skulachev ${ }^{\mathrm{b}, \mathrm{c}}$ and Nataliya G. Kolosova ${ }^{\mathrm{a}, \mathrm{b}}$ \\ anstitute of Cytology and Genetics, Novosibirsk, Russia \\ ${ }^{\mathrm{b}}$ Institute of Mitoengineering, Moscow, Russia \\ ${ }^{\mathrm{c}}$ Belozersky Institute of Physico-Chemical Biology and Faculty of Bioengineering and Bioinformatics, \\ Lomonosov Moscow State University, Moscow, Russia
}

Accepted 3 August 2013

\begin{abstract}
We previously showed that mitochondria-targeted antioxidant SkQ1 (plastoquinonyl-decyltriphenylphosphonium) at nanomolar concentrations is capable of preventing and slowing down some cerebral dysfunctions in accelerated-senescence OXYS rats. Here we demonstrate that OXYS rats develop behavior, learning, and memory deficits against a background of neurodegeneration signs detected by magnetic resonance tomography and amyloid- $\beta$ (A $\beta$ ) pathology similar to those seen in Alzheimer's disease (AD). Long-term treatment with SkQ1 ( $250 \mathrm{nmol} / \mathrm{kg}$ body weight daily from the age of 1.5 to 23 months) reduced the age-related alterations in behavior and spatial memory deficit in Morris water maze in OXYS and Wistar rats. Furthermore, this is the first report that SkQ1 treatment slows down pathological accumulation of A $\beta P P, A \beta$, and hyperphosphorylation of tau-protein in OXYS rats, as well as age-dependent changes in healthy Wistar rats. Our results support the possibility of using the OXYS strain as a rat model of AD-like pathology. It seems probable that the mitochondria-targeted antioxidant SkQ1 can be a good prophylactic strategy to maintain brain health and to treat AD.
\end{abstract}

Keywords: Alzheimer's disease, brain aging, mitochondria-targeted antioxidant SkQ1, senescence-accelerated OXYS rats

\section{INTRODUCTION}

Alzheimer's disease (AD) is the most common agerelated neurodegenerative disorder characterized by progressive memory loss, decline in cognitive function, and eventual death, which affects more than 35 million people worldwide [1]. Mitochondrial dysfunction and oxidative stress are two interdependent and reinforcing damage mechanisms that play a central role not

*Correspondence to: Natalia A. Stefanova, Institute of Cytology and Genetics, Prospekt Lavrentyeva 10, 630090 Novosibirsk, Russia. Tel: +7 38336349 80; Fax: +7 38333312 78; E-mail: stefanovan@bionet.nsc.ru. only in brain aging but also in AD [2-5]. Yet it has not been established that the increased oxidative stress in aging brain results from (i) accumulation of prooxidant factors which increase production of reactive oxygen species (ROS) from different sources, or (ii) a fall in activity of some antioxidant enzymes and (iii) a combination of these factors [4]. In particular, it was found that amyloid- $\beta$ peptide $(A \beta)$ derived from $A \beta P P$ (amyloid- $\beta$ protein precursor), the major pathological hallmark of $\mathrm{AD}$, operates as a pro-oxidant $[6,7]$. $\mathrm{A} \beta$ stimulates phosphorylation of tau protein through glycogen synthase kinase, leading to neurofibrillary tangles, an effect directly causing synaptic damage and memory impairment. Formation of the amyloid 
plaques damages the blood-brain barrier, resulting in trapping $A \beta$ within the brain, excitotoxicity, inflammation, oxidative stress, and stimulation of apoptosis [8]. A $\beta$ binds to mitochondrial membranes, interacts with hemes, and thus inhibits electron flow in the respiratory chain [9-12]. Moreover, oxidative stress has been shown to precede and exacerbate $A \beta$ pathology $[6,8]$. Accordingly, the ability of drugs to prevent $\mathrm{A} \beta$ pathology may be crucial to the development of effective AD therapies [13]. Recent studies have provided substantial evidence that mitochondria-targeted antioxidants are promising in treatment of $\mathrm{AD}$ and other ROS-mediated brain pathologies [5].

We showed previously that mitochondria-targeted antioxidant SkQ1 (plastoquinonyl-decyltriphenylpho sphonium) at nanomolar concentrations is capable to prevent and slow down some consequences of accelerated-senescence in OXYS rats [14-20], including brain aging [21]. The manifestations of accelerated brain aging in OXYS rats are behavioral alterations and learning and memory deficits that develop since 4 th week of age [21-24], i.e., simultaneously with first signs of neurodegeneration detected by magnetic resonance imaging (MRI) $[25,26]$. Also, impaired long-term potentiation has been demonstrated in OXYS rats at 3 months of age and older [27]. The $\mathrm{A} \beta$-induced inhibition of long-term potentiation was shown to be abolished by SkQ1 [28]. It was also shown in our group that the progressive mitochondrial dysfunction plays a major role in accelerated aging and in the development of oxidative stress-associated diseases in OXYS rats [24, 29-31].

Here we present MRI assessment of age-related alterations in the brain of OXYS rats and evidence that neurodegenerative changes in OXYS rats mimic the AD-like pathology. Further, we show that a long-term treatment with the mitochondria-targeted antioxidant SkQ1 corrects the AD-like pathology in OXYS rats as well as the brain aging of Wistar rats.

\section{MATERIALS AND METHODS}

\section{Animals and diet}

Male senescence-accelerated OXYS $(n=70)$ and age-matched male Wistar $(n=70)$ rats were obtained from the Breeding Experimental Animal Laboratory of the Institute of Cytology and Genetics, Siberian Branch of the Russian Academy of Sciences (Novosibirsk, Russia). The OXYS rat strain was developed at the Institute of Cytology and Genetics from Wistar stock by selection for susceptibility to cataractogenic effect of a galactose-rich diet and inbreeding of highly susceptible rats. After five cycles of inbreeding, feeding galactose-rich diet and selection, the resulting generations of rats developed cataracts spontaneously without galactose supplementation of the diet. These rats were registered in the Rat Genome Database as the OXYS rat strain (http://rgd.mcw.edu/). At this point, we have the 102th generation of OXYS rats with spontaneously developing cataract and accelerated senescence syndrome inherited in a linked manner. Cataract still serves as the key parameter for controlling the state of OXYS strain whereas the other features of accelerated senescence observed in these animals, including cognitive and affective alterations, appeared to be concomitant. At the age of 4 weeks, the pups were weaned, housed in groups of five animals per cage $(57 \times 36 \times 20 \mathrm{~cm})$, and kept under standard laboratory conditions $\left(22^{\circ} \mathrm{C} \pm 2{ }^{\circ} \mathrm{C}\right.$, $60 \%$ relative humidity, and natural lighting). The animals were provided with standard rodent feed (PK-120-1, Ltd, Laboratorsnab, Russia) and water ad libitum.

To study the influence of long-term treatment with SkQ1 (from the age of 1.5 months to the age of 23 months) on age-related neurodegenerative changes, 1.5-month-old males of OXYS and Wistar rats were randomly assigned to one of the two groups (15 rats of each strain): provided with either the control diet or the diet supplemented with $250 \mathrm{nmol} \mathrm{SkQ1} \mathrm{per} \mathrm{kg} \mathrm{of} \mathrm{body}$ weight per day. Each rat received SkQ1 are individually daily. The weight gain was measured in the course of the experiment for adjustment of the SkQ1 dose. The body weight was significantly higher in Wistar rats than in OXYS rats in the course of the experiment $(p<0.05)$. SkQ1 treatment did not affect body weight in both OXYS and Wistar rats $(p>0.05)$.

All experimental procedures were in compliance with the European Communities Council Directive of 24 November 1986 (86/609/EEC). All efforts were made to minimize the number of animals used and their suffering.

\section{MRI study}

The rats of both strains at 3,13 and 23 months of age $(n=8)$ were used for the study of age-dependent neurodegenerative changes detected by MRI in the Inter-institutional research sector for imaging of laboratory animals. All MRI experiments were performed on a horizontal 11.7T magnet (Bruker, BioSpec 117/16 USR, Germany) interfaced with a digital spectrometer operating at a resonant frequency of $500 \mathrm{MHz}$. The 
system is equipped with a 90 -mm actively-shielded gradient set, with a maximum gradient strength of $740 \mathrm{mT} / \mathrm{m}$. Radio frequency (RF) excitation was accomplished with a 72-mm inner diameter (ID) linear birdcage coil, and signal reception was achieved using a 45-mm ID surface coil. Each rat was anesthetized by injecting sodium thiopental $(60 \mathrm{mg} / \mathrm{kg}$ intraperitoneal) before the MRI experiment. The animals were placed in the prone position and then slid into the magnet bore with an animal bed. A respiratory pillow placed underneath the lower torso was used to monitor respiration (SA Instruments, Stony Brook, NY, USA).

The T2-weighed images TR, $2500 \mathrm{~ms}$; TE, $11 \mathrm{~ms}$; TEeff, $33 \mathrm{~ms}$; number of averages, 2; RARE factor, 8; number of slices, 23; slice orientation, axial; slice thickness, $0.5 \mathrm{~mm}$; inter-slice gap, $1.0 \mathrm{~mm}$; field of view, $3 \times 3 \mathrm{~cm}$; matrix, $256 \times 256$; scan duration, 2 min 40 s; rapid-acquisition relaxation-enhancement pulse sequence was used.

The lateral ventricle was selected using the manufacturer's Region of Interest (ROI) Tool software and a standard rat brain atlas by Swanson LW (2004) (Brain Maps: Structure of the Rat Brain, Third Edition, Elsevier, Amsterdam). The foci of demyelination were visualized as hyper intense areas on the T2-weighed images.

\section{Behavioral testing}

Behavioral testing was carried out after $1.5,11.5$ and 14.5 months of the SkQ1 treatment when rats reached the age of 3,13 and 16 months, respectively. Behavioral responses of animals to treatment were assessed in several tests in the following order: assessment of the degree of anxiety in the elevated plus-maze (EPM) and locomotor and exploratory activity in an open field (OF) [32]. Each test was performed twice for each animal at 3 and 13 months of age $(n=15)$. The spatial memory task in the Morris water maze (MWM) was assessed for each animal at 3,13 and 16 months of age $(n=8)$. The test sessions were conducted between 10 a.m. and 2 p.m. [33].

\section{Elevated plus-maze test}

The test was performed as described by Redrobe et al. [34]. The plus-maze apparatus was made of opaque Plexiglas and contained two opposite open $\operatorname{arms}(50 \times 10 \mathrm{~cm})$ and two closed arms of the same size but with $40-\mathrm{cm}$ high walls. The four arms were connected by a central square $\left(10 \mathrm{~cm}^{2}\right)$ and thus formed a plus sign. The apparatus was elevated $50 \mathrm{~cm}$ above the floor. Each rat was placed in the central square of the plus maze facing one of the closed arms and its behavior was analyzed for $5 \mathrm{~min}$. The number of entries with all four arms into the EMP arms and the time spent in the EMP arms were recorded. A greater amount of time spent in the open arms indicated reduction of anxiety-like behavior.

\section{Open field test}

Forty eight hours after completion of the elevated plus-maze test, the animals were subjected to the open field test [34]. The open field area consisted of an enclosed square arena made of opaque Plexiglas $(100 \times 100 \mathrm{~cm})$ surrounded by walls $(40 \mathrm{~cm}$ high $)$. The arena was divided by transverse lines into 100 equal squares. A central light source $(100 \mathrm{~W})$ on the ceiling gave invariant illumination in an otherwise dark room. A rat to be tested was transported from the home cage to the recording room in a black box. Each rat was gently placed into the same corner of the arena facing in the same direction and allowed to freely explore the arena for $5 \mathrm{~min}$. Every time both hind limbs entered a square, a crossing was recorded. The locomotor and exploratory activity was evaluated by means of measurements of the number of line crossings and the number of rearings (the number of times an animal stood on its hind limbs).

\section{Morris water maze test of spatial memory}

The Morris water maze test was employed to analyze spatial memory by requiring rats to find a submerged platform in a pool of water, using external visual cues [35]. Animals were trained in a circular pool $(180 \mathrm{~cm}$ in diameter) located in a well-lit room with visual cues. An escape platform $\left(13 \mathrm{~cm}^{2}\right)$ was submerged $2.0 \mathrm{~cm}$ below the surface of the pool water, which was maintained at $22 \pm 2{ }^{\circ} \mathrm{C}$, and mixed with milk powder to obscure the platform. The location of the platform remained in the center of northwest quadrant throughout the 5-day training period. Trials (5 consecutive days, 4 trials per day) were conducted with the same hidden platform location but with varied start locations. Each trial either lasted for $70 \mathrm{~s}$ or ended sooner when the rat reached the submerged platform thus escaping from water. If the rat failed to find the platform within $70 \mathrm{~s}$, it was placed on the platform by the investigator. Whether the rat found the platform or was placed on it, the animal was allowed to rest on the platform 
for $20 \mathrm{~s}$. Latencies in finding the submerged escape platform were recorded with a computerized video system.

\section{Sample collection for protein analysis}

To determine the content of $A \beta_{42}, A \beta P P$, tau and phospho-tau protein in the brain, we used untreated rats from each strain at 3,13 and 23 months of age or 23-month-old SkQ1-treated OXYS and Wistar rats $(n=8-10)$. The hippocampus and frontal cortex were quickly separate from the brain, placed in microcentrifuge tubes for protein isolation, and frozen in liquid nitrogen. All specimens were stored at $-70^{\circ} \mathrm{C}$ before the analysis. Frozen tissues of the hippocampus and frontal cortex were homogenized in the protein lysis buffer RIPA (50 mM Tris-HCl pH 7.4, $150 \mathrm{mM} \mathrm{NaCl,}$ $1 \%$ Triton $\mathrm{X}-100,1 \%$ sodium deoxycholate, $0.1 \%$ SDS, and $1 \mathrm{mM}$ EDTA) supplemented with a protease inhibitor cocktail (P8340; Sigma-Aldrich, USA). After incubation for 20 minutes on ice, samples were centrifuged at $12000 \mathrm{~g}$ at $4{ }^{\circ} \mathrm{C}$ for 30 minutes and the supernatants were transferred to new tubes. Total protein was measured using the Bio-Rad Bradford kit (Bio-Rad Laboratories, USA).

\section{Western blotting and enzyme-linked immunosorbent assay (ELISA)}

Approximately $30 \mu \mathrm{g}$ of protein extracts were resolved on $12 \%$ SDS-PAGE in the TGB running buffer ( $25 \mathrm{mM}$ Tris base, $190 \mathrm{mM}$ glycine, and $0.1 \%$ SDS) and transferred to a nitrocellulose membrane. The membrane was blocked with $3 \%$ bovine serum albumin in Tris-buffered saline with $0.1 \%$ Tween 20 (TBS-T) for $1 \mathrm{~h}$, and incubated overnight at $4^{\circ} \mathrm{C}$ with a chicken polyclonal antibody to tau, rabbit polyclonal antibody to tau (phospho-T181), and rabbit polyclonal antibody to A $\beta P P$ (1:1000; Abcam, USA). Secondary antibodies were sheep anti-rabbit IgG-HRP and goat anti-chicken IgG-HRP (1:10000; Abcam, USA). After incubation with the respective second antibodies, the chemiluminescence signal was measured and scanned, and the intensity of the emission bands was quantified using ImageJ (NIH, Bethesda, MD). Beta-actin was always used as internal loading control.

Enzyme-linked immunosorbent assay (ELISA) for amyloid $\beta$ 42(Rat) ELISA Kit (290-62601; Wako, Japan) was performed according to the manufacturer's instructions, and equal protein concentrations were loaded into each well. Quantitation was carried out based on the optical density measurement on a microtiter plate reader and recalculated as $\mathrm{pg}$ of protein amyloid $\beta(1-42)$ per $\mathrm{mg}$ of the hippocampus or cortex tissue.

\section{Statistical analysis}

The data were analyzed using repeated measures analysis of variance (ANOVA) and nonparametric tests with the statistical package Statistica 6.0 (USA). Two-way ANOVA was used to evaluate the differences between OXYS and Wistar rats across ages (age $\times$ genotype) as well as to evaluate effects of treatment $($ SkQ1 $1 \times$ genotype). To test the effect of the drug on parameters, the genotype and the SkQ1 were chosen as independent variables. A Newman-Keuls post hoc test was applied to significant main effects and interactions in order to estimate the differences between particular sets of means. One-way ANOVA was used for individual group comparisons. Comparisons between means were carried out using one-way or repeated measures ANOVA. Results were considered statistically significant if $p<0.05$.

\section{RESULTS}

\section{MRI assessment of age-related brain alterations}

It was found that the area of lateral ventricles (a sign of hydrocephalus) was affected by age $\left(\mathrm{F}_{2,38}=42.0, p<0.0001\right)$, genotype $\left(\mathrm{F}_{1,38}=152.4\right.$, $p<0.0001)$, and the relationship of these factors $\left(\mathrm{F}_{2,38}=20.3, p<0.0001\right)$. Results showed that 3-, 13-, and 23-month-old OXYS rats had an enlargement of the lateral ventricles, about 3- to 4-fold for every age, compared to Wistar rats $(p<0.05$, Fig. 1A, B). Between 3 and 13 months of age and between 13 and 23 months of age, the area of lateral ventricles in OXYS rats increased significantly $(p<0.05)$, while in Wistar rats there were significant changes only between 13 and 23 months of age $(p<0.05)$.

MRI showed no foci of demyelination in the brain of 3-month-old Wistar rats but between 13 and 23 months of age this index increased from $33 \%$ to $67 \%$. As to OXYS rats, they showed signs of the presence of foci of demyelination in $75 \%$ of 3-month-old and $100 \%$ of 13- and 23-month-old animals (Fig. 2A, C). Effects of age and genotype on the number of demyelinating foci were statistically reliable (for age, $\mathrm{F}_{2,38}=6.1, p<0.006$ and for genotype, $\mathrm{F}_{1,38}=38.4$, $p<0.001$ ). The 3-, 13-, and 23-month-old OXYS rats had the higher level of demyelinating foci compared to Wistar rats $(p<0.05)$. There were no statistically 

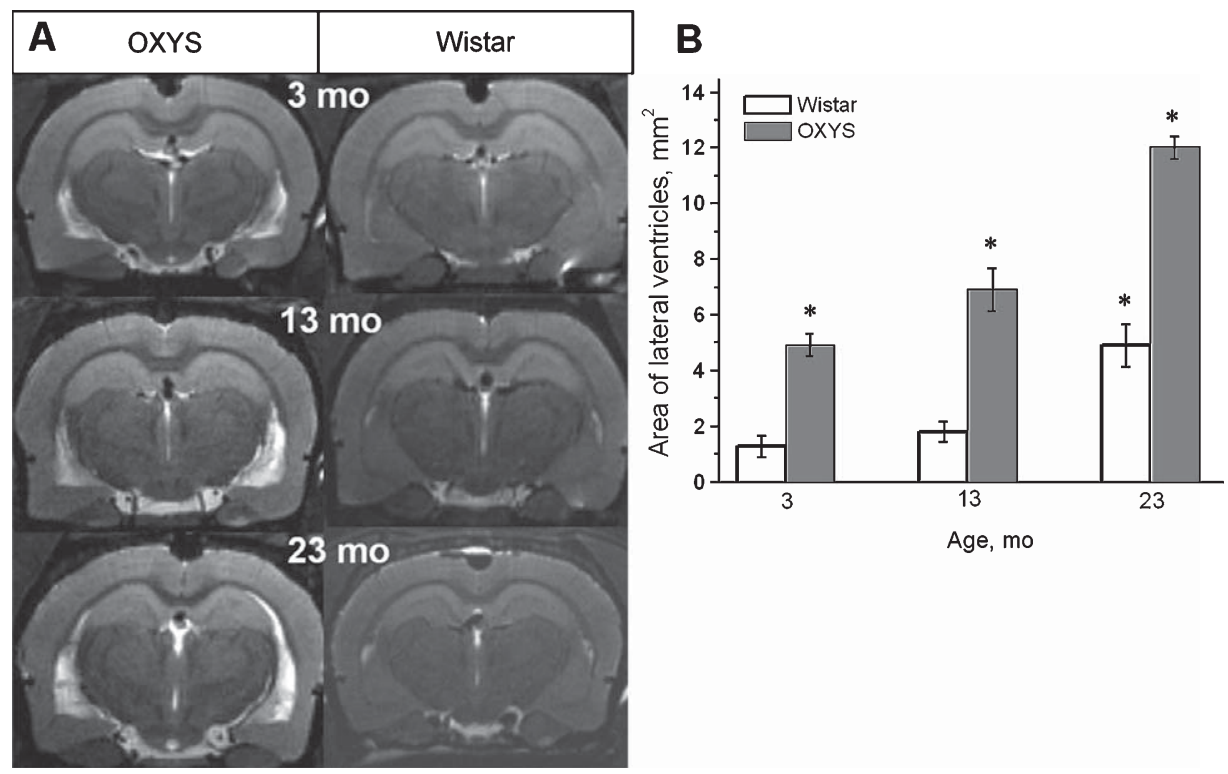

Fig. 1. The T2-weighed MRI images of lateral ventricles in 3-, 13-, and 23-month-old Wistar and OXYS rats untreated with SkQ1. (A) Axial slices of the brain of 3-, 13-, and 23-month-old untreated Wistar and OXYS rats. Increases in the size of lateral ventricles in OXYS rats are visible (the arrows); (B) 3-, 13-, and 23-month-old OXYS rats have an enlargement of the lateral ventricles compared to Wistar rats. The data are shown as mean \pm S.E.M. ${ }^{*} p<0.05$ for differences between the strains.
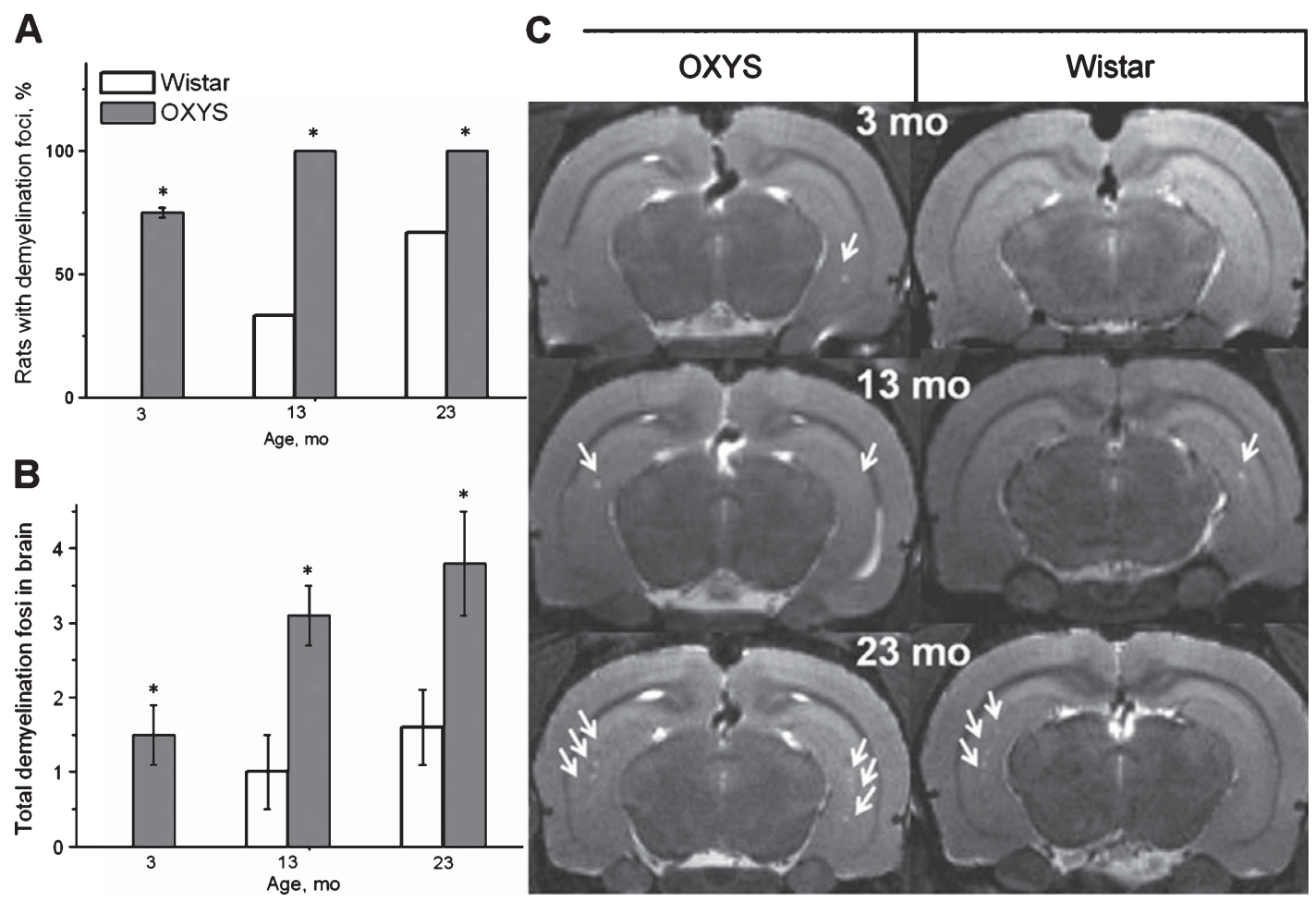

Fig. 2. The T2-weighed MRI images of demyelinating foci in 3-, 13-, and 23-month-old intact Wistar and OXYS rats. (A) The presence of foci of demyelization in 3-, 13-, and 23-month-old intact Wistar and OXYS rats (\% animals); (B) OXYS rats have a greater number of demyelinating foci compared to Wistar rats; (C) Axial slices of the brain of 3-, 13-, and 23-month-old Wistar and OXYS rats untreated with SkQ1. The arrows point to foci of demyelization. The data are shown as mean \pm S.E.M. ${ }^{*} p<0.05$ for differences between the strains. 
significant age-related differences in this parameter in Wistar rats.

Age-related behavior alterations and effects of SkQ1

\section{Elevated plus-maze}

3-month-old OXYS rats showed a significantly lower number of entries into open EPM arms $\left(\mathrm{F}_{1,52}=6.2, p<0.02\right)$ and time spent there $\left(\mathrm{F}_{1,52}=6.3\right.$, $p<0.02)$ compared with age-matched Wistar rats (Fig. 3A, B). In addition, OXYS rats had significantly less enters into closed arms and more time spent there $\left(\mathrm{F}_{1,52}=15.2, p<0.0004\right.$ and $\mathrm{F}_{1,52}=4.2$, $p<0.048$, respectively; Fig. 3C, D). 13-month-old Wistar and OXYS rats spent significantly less time in the open arms $(p<0.0001$ and $p<0.013$, respectively) and consequently more time in the closed arms $(p<0.0001$ and $p<0.013$, respectively) when compared with 3-month-old animals. Nevertheless, these indexes did not significantly differ between 13-monthold OXYS and Wistar rats $\left(\mathrm{F}_{1,52}=4.0, p=0.052\right.$ for the number of open arms entries and $\mathrm{F}_{1,52}=1.0, p=0.32$ for time spent there; $\mathrm{F}_{1,52}=3.1, p=0.08$ for the number of closed arms entries and $\mathrm{F}_{1,52}=0.9, p=0.35$ for time spent there). Such relationships were due to a high level $86 \%$ of "freezing" in OXYS rats, typical for this rat strain as nonspecific behavioral response to a stressful situation in the EPM [21, 24, 36].

After 1.5 months of treatment with SkQ1, the number of open arms entries and time spent there in 3-month-old OXYS rats were greater than in Wistar rats but the difference was not statistically reliable. Based on the EPM data, SkQ1-treated 3-monthes-old OXYS and untreated Wistar rats did not differ (Fig. 3). SkQ1 did not affect activity of young Wistar rats.

Long-term treatment with SkQ1 by the age of 13 months slowed the age-dependent effects of aging, e.g., the time spent in open arms, which increased 4.4 fold in Wistar rats $(p<0.03)$ and 3 fold in OXYS rats (statistically not reliable, Fig. 3B). In addition, in SkQ1-treated Wistar rats, the time spent in the closed arms decreased $(p<0.04)$.

\section{Open field}

The results of the behavioral analysis in the OF test are presented in Fig. 4. Both 3- and 13-monthold OXYS rats had significantly less locomotor and exploration activities in OF than did age-matched Wistar rats. These differences manifested themselves as a significantly reduced number of squares crossed $\left(\mathrm{F}_{1,52}=59.4, p<0.001\right.$ and $\mathrm{F}_{1,48}=92.2, p<0.0001$, respectively) and frequency of rearing $\left(\mathrm{F}_{1,52}=82.6\right.$, $p<0.001$ and $\mathrm{F}_{1,48}=52.1, p<0.001$, respectively).

A paired comparison showed significantly lower activity in OXYS and Wistar rats at age 13 months compared to the age of 3 months in the number of linecrossings $(p<0.002$ and $p<0.0013$, respectively) and rearings ( $p<0.002$ and $p<0.0009$, respectively).

After 1.5 months of treatment with SkQ1, the number of squares crossed by OXYS rats was significantly higher than that in the untreated group $(p<0.0001)$. In 3-month-old Wistar rats treated with SkQ1 we found no such difference. Long-term treatment with SkQ1 significantly slowed the age-dependent decrease of locomotor activity in Wistar and OXYS rats ( $p<0.0001$ for both rat strains, Fig. 4A). Only SkQ1treated 13-month-old Wistar rats showed a significant increase in rearings $(p<0.03)$, whereas in OXYS rats, the increase was not statistically reliable (Fig. 4B).

\section{Morris water maze}

The learning and memory were tested using the MWM in 3-, 13-, and 16-month-old Wistar and OXYS rats (Fig. 5). Rats are rather good swimmers. Moreover, they are motivated to escape from water based on visual references. Once animals learn where the hidden platform is located, they can remember the location and swim rapidly to it from any starting point. In Wistar rats, the ability to learn did not differ significantly between the ages of 3,13 and 16 months (Fig. 5A), whereas in OXYS rats it decreased with age $(p<0.05)$, which reflects gradual deterioration of cognitive functions (Fig. 5B). Post-hoc analysis suggested that the escape latency in 16-month-old OXYS rats was significantly longer than that of Wistar rats $(p<0.05)$. In addition, it is noteworthy that OXYS rats showed a significantly reduced learning ability on the first three days only $(p<0.01, p<0.02$ and $p<0.004$, respectively).

Long-term treatment with SkQ1 had no significant effect on the escape latency in Wistar rats who exhibited the ability to learn unchanged since age 3 months. In OXYS rats, the SkQ1 treatment showed a tendency to increase learning (Fig. 5B).

\section{Age-related alterations in the AD-like metabolic pathway and effects of $S k Q 1$}

\section{$A \beta P P$ and $A \beta$ levels}

Western blot analysis data for A $\beta P P$ levels in the brain of OXYS and Wistar rats (3-, 13-, and 23months-old control and SkQ1-treated animals) are shown in Fig. 6. It was shown that A $\beta P P$ protein 

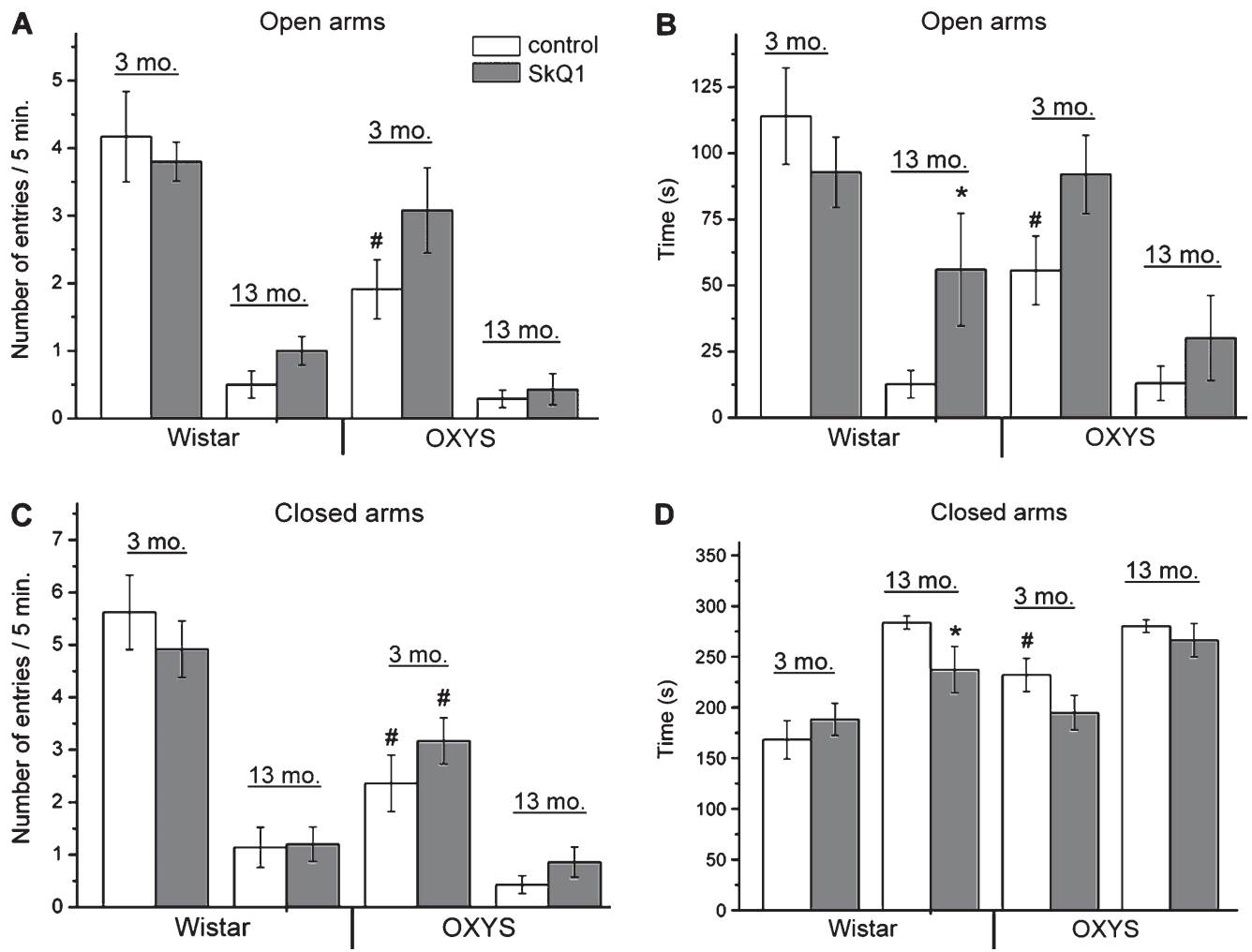

Fig. 3. Elevated plus maze (EPM) performance in 3- and 13-month-old control and SkQ1-treated rats. OXYS rats at 3 months of age have a reduced number of entries into open (A), closed arms (C) and time spent there (B, D) in comparison with age-matched Wistar rats. The indexes in panels A-C decrease, and time spent in closed arms (D) increases with age in both 13-month-old Wistar and OXYS rats. SkQ1 significantly increases the time spent in open arms and decreases the time spent in closed arms in 13-month-old Wistar rats. The data are shown as mean \pm S.E.M. ${ }^{*} p<0.05$ for differences between the strains; ${ }^{*} p<0.05$ for effects of SkQ1.
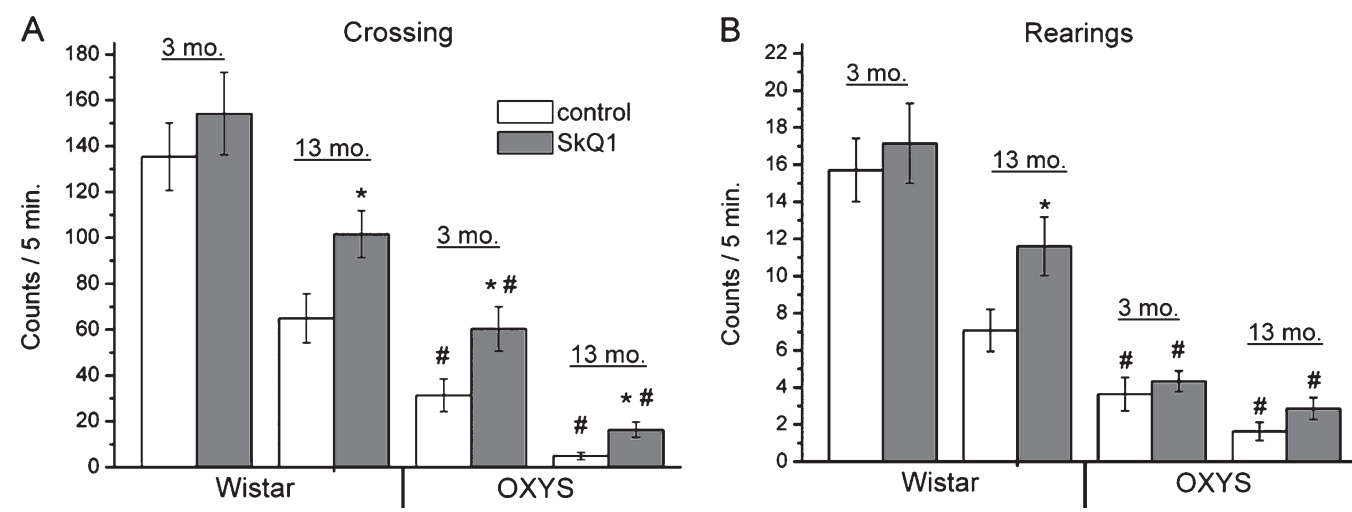

Fig. 4. Open field (OF) performance in 3-and 13-month-old control and SkQ1-treated rats. 3- and 13-month-old OXYS rats have a reduced number of squares crossed (A) and reduced frequencies of rearing (B) compared to age-matched Wistar rats. SkQ1 significantly increases the number of squares crossed in 3- and 13-month-old OXYS rats. SkQ1-treated Wistar rats at the age of 13 months have a greater number of squares crossed and a greater frequency of rearing than rats of the control group. The data are shown as mean \pm S.E.M. ${ }^{\#} p<0.05$ for differences between the strains; ${ }^{*} p<0.05$ for effects of SkQ1.

content in the cortex and hippocampus was affected by age $\left(\mathrm{F}_{1,46}=33.1, p<0.001\right.$ and $\mathrm{F}_{1,46}=30.7, p<0.001$, respectively), by genotype $\left(\mathrm{F}_{1,46}=17.6, p<0.001\right.$ and $\mathrm{F}_{1,46}=17.5, p<0.001$, respectively), and by the rela- tionship of these factors $\left(\mathrm{F}_{1,46}=4.6, p<0.014\right.$ and $\mathrm{F}_{1,46}=3.7, p<0.03$, respectively). Our results also showed that content of $\mathrm{A} \beta \mathrm{PP}$ in the hippocampus and cortex did not differ between the strains at 3 months 

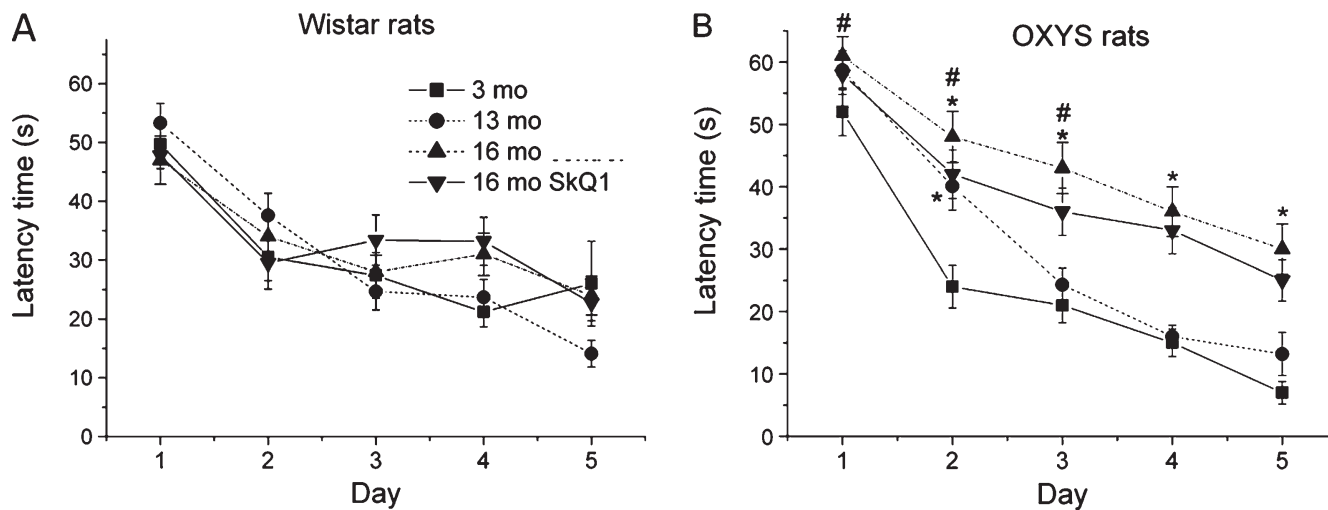

Fig. 5. The age-dependent changes in spatial learning performance and effects of SkQ1 on spatial memory of Wistar and OXYS rats in the Morris water maze (MWM) test. (A) In 3-, 13-, and 16-month-old Wistar rats the learning capacity does not change significantly. Treatment with SkQ1 has no significant effect on the escape latency in Wistar rats, which have the capacity to learn unchanged since age 3 months. (B) In OXYS rats, the learning ability decreased since the age of 13 months, pointing to a gradual decline of cognitive function. SkQ1 treatment from the age of 1.5 to 16 months slows the learning and memory decline with age in OXYS rats. The data are shown as mean \pm S.E.M. ${ }^{\#} p<0.05$ for differences between the strains; ${ }^{*} p<0.05$ for age-related differences within a strain.

of age and then increased with age in both strains. 13and 23-month-old OXYS rats had the highest levels of A $\beta P P$ in both hippocampus and cortex compared to those in Wistar rats $(p<0.05)$.

Treatment with SkQ1 from the age of 1.5 months to the age of 23 months significantly slowed the increase in levels of $\mathrm{A} \beta \mathrm{PP}$ in the cortex and hippocampus of OXYS rats $(p<0.038$ and $p<0.001$, respectively), but not in Wistar rats. As a result, the A $\beta P P$ levels in the cortex and hippocampus of 23-month-old SkQ1-treated OXYS rats was lower than those in 13month-old rats and similar to the level in Wistar rats (age 23 months, Fig. 6).

ELISA data for $A \beta_{42}$ levels in the brain of OXYS and Wistar rats (3-, 13-, and 23-month-old control and SkQ1-treated animals) are shown in Fig. 7. It

A Frontal cortex

Hippocampus

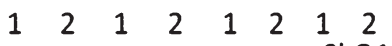
+ SkQ1
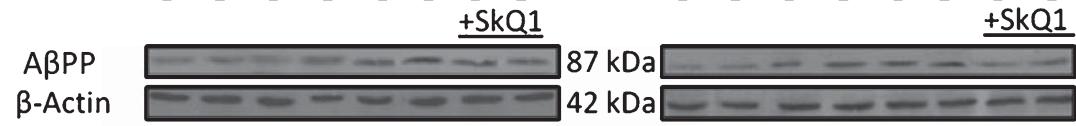

$3 \mathrm{mo} .13 \mathrm{mo} .23 \mathrm{mo}$.
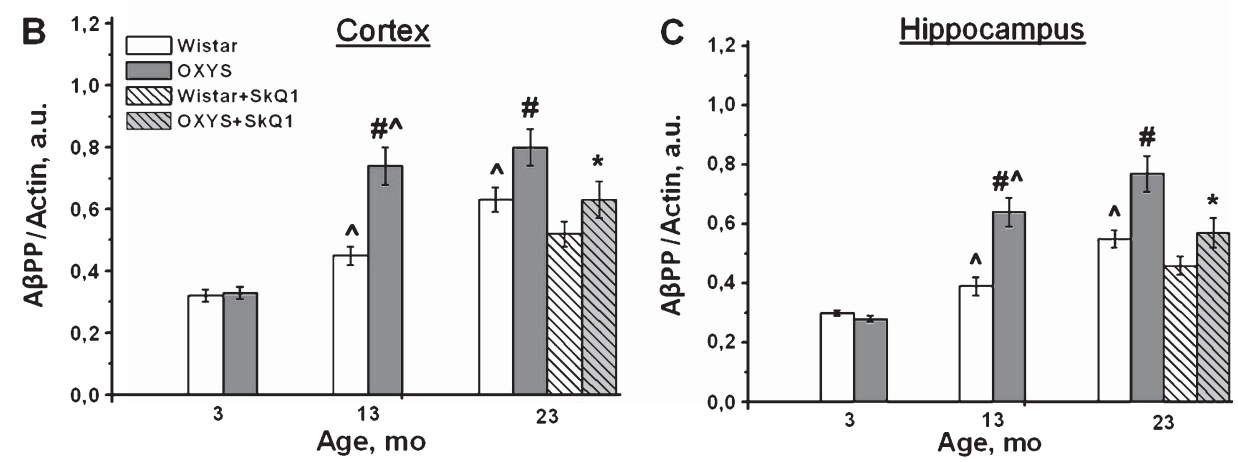

Fig. 6. Age-related alterations in amyloid- $\beta$ protein precursor (A $\beta P P$ ) levels and effects of SkQ1. (A) Levels of A $\beta P P$ protein in the cortex and hippocampus of Wistar (lane 1) and OXYS (lane 2) rats (3-, 13-untreated and 23-month-old control and SkQ1-treated animals) according to immunoblot analysis. The relative quantity of A $\beta P P$ protein was calculated as intensity of an A $\beta P P$ band divided by intensity of a $\beta$-actin band in the cortex (B) and hippocampus (C). The data are shown as mean \pm S.E.M. ${ }^{\#} p<0.05$ for differences between the strains; $p<0.05$ for age-related differences within a strain; ${ }^{*} p<0.05$ for effects of SkQ1. 

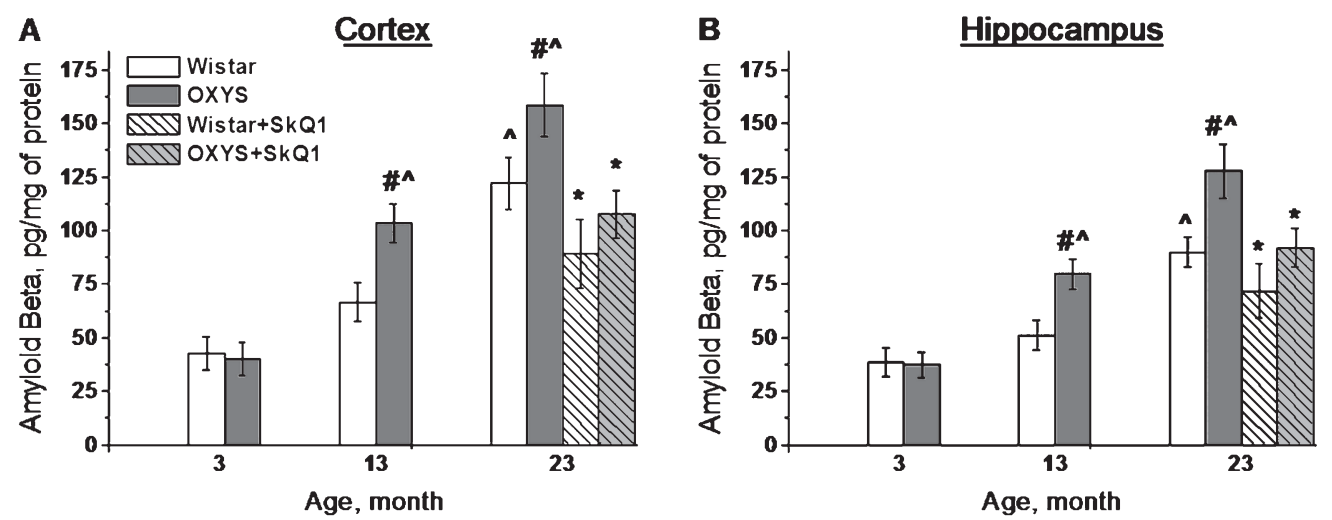

Fig. 7. Age-related alterations in amyloid- $\beta_{42}$ peptide $\left(A \beta_{42}\right)$ levels and effects of SkQ1. Levels of $A \beta_{42}$ in the cortex (A) and hippocampus (B) of Wistar and OXYS rats (3-, 13-untreated and 23-month-old control and SkQ1-treated animals) according to ELISA. The data are shown as mean \pm S.E.M. ${ }^{\#} p<0.05$ for differences between the strains; $p<0.05$ for age-related differences within a strain; ${ }^{*} p<0.05$ for effects of SkQ1.

was found that $A \beta_{42}$ levels in cortex and hippocampus were affected by age $\left(\mathrm{F}_{2,32}=45.3, p<0.001\right.$ and $F_{2,32}=52.0, p<0.001$, respectively) and genotype $\left(\mathrm{F}_{1,32}=7.6, p<0.01\right.$ and $\mathrm{F}_{1,32}=11.3, p<0.002$, respectively). Our results showed that 13 - and 23 month-old OXYS rats had the highest level of $A \beta_{42}$ in both hippocampus and cortex compared to Wistar rats $(p<0.05)$. In addition, in this strain $\mathrm{A} \beta_{42}$ levels increased significantly $(p<0.05)$ between 3 and 13 months of age and 13 and 23 months of age, while in Wistar rats the increase was significant only between 13 and 23 months of age $(p<0.05)$.

Long-term treatment with SkQ1 by the age of 23 months significantly slowed the age-dependent accumulation of $A \beta_{42}$ in the cortex and hippocampus of both rat strains $\left(\mathrm{F}_{1,40}=13.7, p<0.001\right.$ and $\mathrm{F}_{1,40}=11.5, p<0.002$, respectively). As a result, the $\mathrm{A} \beta_{42}$ levels in the cortex and hippocampus of 23month-old SkQ1-treated OXYS rats were similar to those in the 13-month-old control animals. Also, SkQ1-treated OXYS rats and untreated Wistar rats of the same age (23 months) did not differ in $\mathrm{A} \beta_{42}$ levels (Fig. 7A, B).

\section{Tau and phospho-tau protein levels}

Western blot analysis data for tau protein and phospho-T181 tau in the brain of OXYS and Wistar rats (3-, 13-, and 23-month-old control and SkQ1-treated animals) are shown in Fig. 8. It was revealed that the tau protein content in cortex and hippocampus of both rat strains was affected by age $\left(\mathrm{F}_{1,51}=6.9, p<0.002\right.$ and $\mathrm{F}_{1,51}=6.8, p<0.002$, respectively) and genotype $\left(\mathrm{F}_{1,51}=23.8, p<0.001\right.$ and $\mathrm{F}_{1,51}=24.5, p<0.001$, respectively). The phospho-T181tau content in cor- tex and hippocampus of OXYS and Wistar rats was affected by age $\left(\mathrm{F}_{1,51}=8.7, p<0.05\right.$ and $\mathrm{F}_{1,51}=8.8$, $p<0.001$, respectively) and genotype $\left(\mathrm{F}_{1,51}=22.3\right.$, $p<0.001$ and $\mathrm{F}_{1,51}=22.5, p<0.001$, respectively). The levels of tau protein and phospho-T181 tau in hippocampus and cortex of OXYS rats were significantly increased at 3,13 and 23 months of age compared to Wistar rats $(p<0.05)$. The content of tau protein and phospho-T181 tau in both hippocampus and cortex of Wistar rats increased by 13 month of age $(p<0.05)$ and stayed at the same level until age 23 months, while in OXYS rats these parameters increased strongly with age $(p<0.05)$.

Long-term SkQ1 treatment significantly slowed the increase in content of tau protein and phospho-T181 tau in cortex ( $p<0.006$ and $p<0.004$, respectively) and hippocampus of 23-month-old OXYS rats $(p<0.01$ and $p<0.008$, respectively), but not of Wistar rats. As a result, the levels of tau protein and phospho-T181 tau in the cortex and hippocampus of 23-month-old SkQ1treated OXYS rats was lower than in 13-month-old rats and similar to the level in untreated Wistar rats (Fig. 8).

\section{DISCUSSION}

To date, there is no perfect rodent model able to fully mimic human neurodegenerative diseases and particularly AD [37]. In fact, no transgenic/mutant rodent model can provide an all-encompassing view of the biology of a disease involving changes in cognitive capacities like AD [38].

Here we demonstrated that OXYS rats develop learning and memory deficits along with neurodegeneration signs and $A \beta$ pathology similar to those seen in 
A

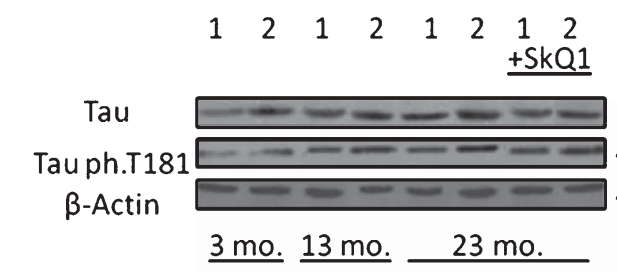

C
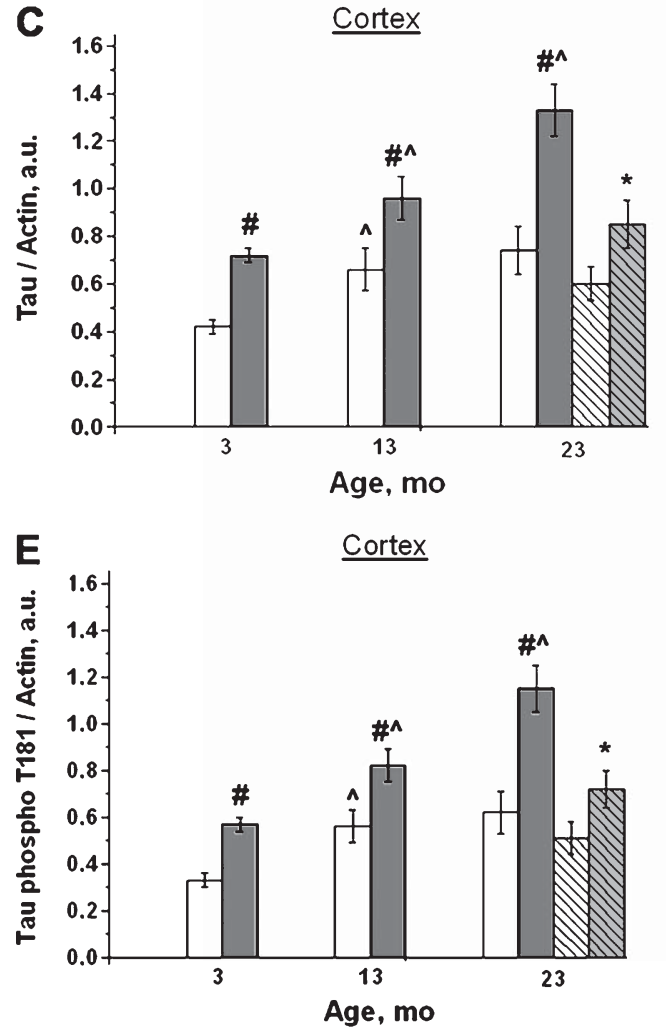

B Hippocampus

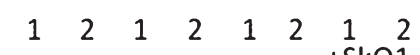

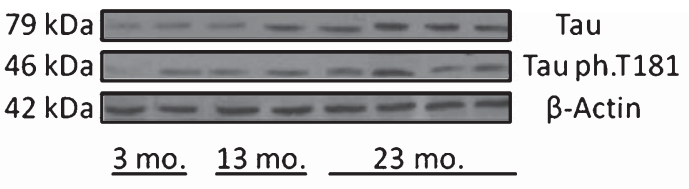

D Hippocampus

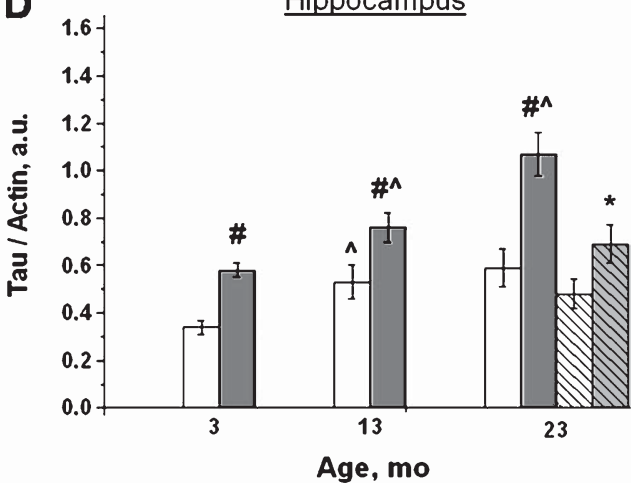

F Hippocampus

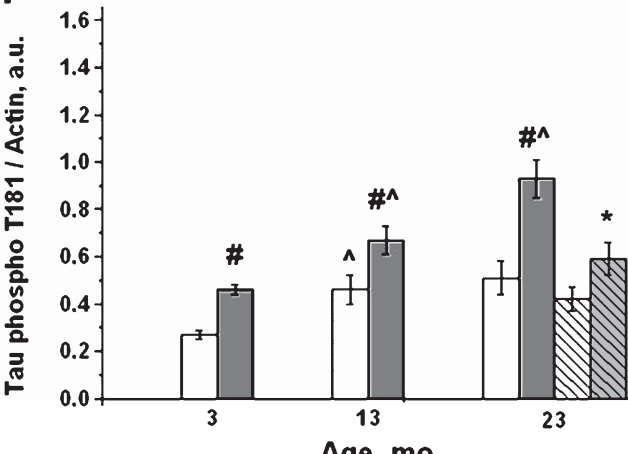

Age, mo

Fig. 8. Age-related alterations in total tau protein and phospho-tau levels and effects of SkQ1. Levels of tau and phosphor-T181 tau in the cortex (A) and hippocampus (B) of Wistar (lane 1) and OXYS (lane 2) rats (3-, 13-untreated and 23-month-old control and SkQ1-treated animals) according to immunoblot analysis. The relative quantity of the total tau protein was calculated as intensity of a tau band divided by intensity of a $\beta$-actin band in the cortex (C) and hippocampus (D). Phosphorylation status of tau protein was calculated as intensity of a phospho-T181 band divided by intensity of a $\beta$-Actin band in the cortex (E) and hippocampus (F). The data are shown as mean \pm S.E.M. ${ }^{\#} p<0.05$ for differences between the strains; $p<0.05$ for age-related differences within a strain; ${ }^{*} p<0.05$ for effects of SkQ1.

AD. Furthermore, this is the first report that SkQ1 treatment slows down accelerated $A \beta$ pathology in OXYS rats, as well as in healthy Wistar rats.

Behaviorally, aged animals show impairments in cognitive, emotional, and motor functions that certainly are the consequence of changes occurring in the brain with age $[8,39,40]$. Here we confirmed our previous results that with aging the exploratory and locomotor activity (EMP and OF tests) decreased, in both Wistar and OXYS rats, with the changes being bigger in OXYS rats [21, 36].
Previously, we showed that SkQ1 treatment in OXYS or Wistar rats lasting 10 weeks strongly diminished the effects of aging on EMP and OF tests in 14-month-old animals $[5,36]$. In this paper, we confirmed this observation. Such a SkQ1 effect is in line with our other finding on the action of natural antioxidants (bilberry extract and vitamin E) in Wistar rats [31].

The learning ability in 3-, 13-, and 16-month-old Wistar rats tested in the MWM were practically the same (see also [21, 36]). However, this ability proved 
to be higher in 3-month-old OXYS rats than in 13- and 16-month-old animals of the same strain. SkQ1 did not have any effect on learning and memory of Wistar rats and slowed their decline with age in OXYS rats.

The behavioral alterations in OXYS rats already at 3 months of age coincided in time with demyelinating lesions identified by MRI. Such lesions were absent from young Wistar rats $[25,26]$. Demyelination occurs both in normal brain aging and in $\mathrm{AD}$, but the magnitude of changes are significantly different [41]. With age, demyelination appeared in Wistar rats, but at 13 and 23 months of age, the number of demyelinating foci was smaller than that in age-matched OXYS rats.

Moreover, according to MRI, the cross-section area of lateral ventricles, which is proportional to their volume, was larger even in 3-month-old OXYS rats and still larger at 13 and 23 months of age compared to aged-matched Wistar rats. Alterations in cerebrospinal fluid dynamics are associated with normal aging and $\mathrm{AD}$ [42]. Enlarged cerebral lateral ventricular volumes are the evidence of early neurodegenerative changes that cause an imbalance between production and turnover of the cerebrospinal fluid, which is also inherent in $\mathrm{AD}$. As a result, with age, cerebrospinal fluid turnover becomes inversely related to brain $A \beta$ accumulation.

The pathological accumulation of $A \beta$ is associated with an imbalance between its production and clearance as a result of disease-causing changes in $\mathrm{A} \beta \mathrm{PP}$ processing [43]. We found that $\mathrm{A} \beta$ gradually accumulated in the hippocampus and cortex of OXYS rats with age. The quantity of A $\beta P P$ protein in the brain of OXYS rats reached a high level by 13 months of age and remained high subsequently. As a result, the content of $A \beta$ and $A \beta P P$ in the hippocampus and cortex of 13- and 23-month-old OXYS rats significantly increased compared to agematched Wistar rats. In addition, learning and memory deficits in the MWM test manifested in the OXYS rats beginning at the age of 13-16 months. It is noteworthy that in 3-month-old OXYS rats (when the behavioral alterations manifested themselves and first signs of neurodegeneration became detectable by MRI), there were no differences in the $A \beta_{42}$ and $\mathrm{A} \beta \mathrm{PP}$ levels in cortex and hippocampus compared to age-matched Wistar rats. In general, in the rodent models of $\mathrm{AD}, \mathrm{A} \beta$ accumulation occurs later than do abnormal behavioral patterns [44-46]. Recently we showed that $A \beta_{42}$ accumulated with age in OXYS rat retina but its level was not elevated at the early stages of retinopathy (age 3 months). The $A \beta_{42}$ level increased in retina of middle-aged and old OXYS rats, when these rats exhibit the severe stages of the disease [47].

It is possible that the increased levels of A $\beta P P$ protein in the cortex and hippocampus of 13-month-old Wistar rats compared with young rats is associated with normal aging. Indeed, our results show that a detectable increase of $A \beta_{42}$ content in the cortex and hippocampus occurs only by age 23 months. Amyloid accumulation in the brain is not only a hallmark of $\mathrm{AD}$ but is also seen in normal aging on a smaller scale [48]. The $A \beta$ protein exists in different assembly states in the central nervous system and plays a role in different processes, such as synapse and memory formation, memory loss, and neuronal cell death $\mathrm{A} \beta$ exists in different assembly states in the central nervous system and plays a role in memory loss and neuronal cell death [49]. Significant decrease in the $A \beta$ efflux transporter expression with age and increase in the influx transporter expression in the blood-brain barrier has been demonstrated [42].

$\mathrm{A} \beta$ is a potent mitochondrial poison [1]. Its toxicity may be related to pro-oxidant effects of this peptide. It is therefore worthwhile to evaluate the effect of the mitochondria-targeted antioxidant SkQ1 on $A \beta$ accumulation in the brain of OXYS rats. Our results show that long-term treatment with SkQ1 significantly decreased the $A \beta$ accumulation in both rat strains and partially prevented overexpression of $A \beta P P$ protein only in OXYS rats. As a result, the $A \beta_{42}$ and A $\beta P P$ levels in cortex and hippocampus of 23month-old SkQ1-treated OXYS rats were similar to the 13-month-old rats of the same strain and to untreated 23-month-old Wistar rats. Recently it was shown in our group that in vivo injection of SkQR1 prevents $A \beta$-induced inhibition of long-term post-tetanic potentiation in Wistar rat hippocampal slices [28].

According to the $\mathrm{A} \beta$ cascade hypothesis, the abnormal accumulation of $A \beta$ leads to mitochondrial dysfunction resulting in production of $\mathrm{mROS}$, which in turn stimulates phosphorylation of tau protein $[5,8]$. In our study, we observed a significant increase in the level of tau protein and its phosphorylation in cortex and hippocampus already seen in 3-month-old OXYS rats compared to Wistar rats; both these parameters were further strongly elevated at 13 and 23 months of age. In Wistar rats, the levels of tau protein and phospho-tau in the brain were increased in adult animals (age 13 months) and stayed at about the same level in old rats (age 23 months). The big changes of tau protein levels in the brain of 3-month-old OXYS rats may also be associated with age-related neurodegeneration. The significant tau and $A \beta$ pathology associated 
with neurodegenerative diseases develops in OXYS rats with age. In this connection, rapidly developing rotenone-induced Parkinson's-like pathology in OXYS rats can be mentioned [26].

Long-term treatment with SkQ1 significantly decreased the level of tau protein and its phosphorylation in cortex and hippocampus in OXYS rats. As a result, the levels of tau protein and phospho-tau in the brain of 23-month-old SkQ1-treated OXYS rats proved to be similar to those in the 13-month-old rats of the same strain and to control Wistar rats.

An alternative hypothesis of $\mathrm{AD}$ development, called the mitochondrial cascade hypothesis, states that damage to mitochondrial DNA results in mitochondrial dysfunction contributing to the accumulation of $\mathrm{A} \beta[8$, $50,51]$. It should also be noted that the abnormal accumulation of $A \beta$ in the brain of OXYS rats by 13 months of age happens after the appearance of mitochondrial dysfunctions, which takes place at 3 months of age, i.e., in the period of phenotypic manifestation of accelerated aging, and increases with age [29, 30]. However, a study of brain energy metabolism by nuclear magnetic resonance spectroscopy has not detected any signs of energy deficiency in the brain of postnatal and young OXYS rats [23]. Lower efficacy of oxidative phosphorylation in the liver mitochondria and the decrease of ATP (adenosine triphosphate) content indicating the energy deficit development were observed in OXYS rats at the age of 12 months. That is exactly the age when we register the increase of $A \beta$ content in the brains of OXYS rats compared to Wistar rats. Therefore, the efficiency of SkQ1 at preventing accelerated senescence in OXYS rats should depend on its ability to prevent mitochondrial dysfunction and energy deficiency.

In conclusion, we observed positive effects of SkQ1 on age-related changes in behavior, learning and memory, pathological accumulation of $A \beta P P$ and $A \beta$, and hyperphosphorylation of tau protein in OXYS rats. Our results support the possibility of using the OXYS strain as a rat model of AD-like pathology. It seems probable that the mitochondria-targeted antioxidant SkQ1 can be a good prophylactic strategy to maintain brain health and to treat AD.

\section{ACKNOWLEDGMENTS}

We are grateful to Drs. M. Moshkin and A. Akulov at the Inter-institutional research sector for imaging of laboratory animals (Institute of Cytology and Genetics and the Institute "International Tomography
Center," Russian Academy of Sciences) for technical assistance with MRI research. The authors thank Dr. E. Rogaev for helpful discussion. This work was supported by grants from Russian Foundation for Basic Research (projects N 11-04-00666 and N 1204-00091) and partially by Grants of the Government of the Russian Federation N 2012-220-03-435 and N 14.B25.31.0033.

Authors' disclosures available online (http://www.jalz.com/disclosures/view.php?id=1897).

\section{REFERENCES}

[1] Querfurth HW, LaFerla FM (2010) Alzheimer's disease. $N$ Engl J Med 362, 329-344.

[2] Navarro A, Boveris A (2010) Brain mitochondrial dysfunction in aging, neurodegeneration, and Parkinson's disease. Front Aging Neurosci 2, 1-11.

[3] McManus MJ, Murphy MP, Franklin JL (2011) The mitochondria-targeted antioxidant MitoQ prevents loss of spatial memory retention and early neuropathology in a transgenic mouse model of Alzheimer's disease. J Neurosci 31, 15703-15715.

[4] Chakrabarti S, Munshi S, Banerjee K, Thakurta IG, Sinha M, Bagh MB (2011) Mitochondrial dysfunction during brain aging: Role of oxidative stress and modulation by antioxidant supplementation. Aging Dis 2, 242-256.

[5] Skulachev VP (2012) Mitochondria-targeted antioxidants as promising drugs for treatment of age-related brain diseases. $J$ Alzheimers Dis 28, 283-289.

[6] Massaad CA (2011) Neuronal and vascular oxidative stress in Alzheimer's disease. Curr Neuropharmacol 9, 662-673.

[7] Massaad CA, Klann E (2011) Reactive oxygen species in the regulation of synaptic plasticity and memory. Antioxid Redox Signal 14, 2013-2054.

[8] Morley JE, Armbrecht HJ, Farr SA, Kumar VB (2012) The senescence accelerated mouse (SAMP8) as a model for oxidative stress and Alzheimer's disease. Biochim Biophys Acta 1822, 650-656.

[9] Butterfield DA, Reed T, Newman SF, Sultana R (2007) Roles of amyloid beta-peptide-associated oxidative stress and brain protein modifications in the pathogenesis of Alzheimer's disease and mild cognitive impairment. Free Radic Biol Med 43, 658-677.

[10] Kilbride SM, Telford JE, Davey GP (2008) Age-related changes in $\mathrm{H} 2 \mathrm{O} 2$ production and bioenergetics in rat brain synaptosomes. Biochim Biophys Acta 1777, 783-788.

[11] Newington JT, Pitts A, Chien A, Arseneault R, Schubert D, Cumming RC (2011) Amyloid beta resistance in nerve cell lines is mediated by the Warburg effect. PLoS One 6, e19191.

[12] Viña J, Lloret A, Giraldo E, Badia MC, Alonso MD (2011) Antioxidant pathways in Alzheimer's disease: Possibilities of intervention. Curr Pharm Des 17, 3861-3864.

[13] Dumont M, Lin MT, Beal MF (2010) Mitochondria and antioxidant targeted therapeutic strategies for Alzheimer's disease. J Alzheimers Dis 20(Suppl 2), 633-643.

[14] Neroev VV, Archipova MM, Bakeeva LE, Fursova AZh, Grigorian EN, Grishanova AY, Iomdina EN, Ivashchenko ZhN, Katargina LA, Khoroshilova-Maslova IP, Kilina OV, Kolosova NG, Kopenkin EP, Korshunov SS, Kovaleva NA, Novikova YP, Philippov PP, Pilipenko DI, Robustova OV, 
Saprunova VB, Senin II, Skulachev MV, Sotnikova LF, Stefanova NA, Tikhomirova NK, Tsapenko IV, Shchipanova AI, Zinovkin RA, Skulachev VP (2008) Mitochondriatargeted plastoquinone derivatives as tools to interrupt execution of the aging program. 4. Age-related eye disease. SkQ1 returns vision to blind animals. Biochem (Mosc) $\mathbf{7 3}$ 1317-1328.

[15] Skulachev VP, Anisimov VN, Antonenko YN, Bakeeva LE, Chernyak BV, Erichev VP, Filenko OF, Kalinina NI, Kapelko VI, Kolosova NG, Kopnin BP, Korshunova GA, Lichinitser MR, Obukhova LA, Pasyukova EG, Pisarenko OI, Roginsky VA, Ruuge EK, Senin II, Severina II, Skulachev MV, Spivak IM, Tashlitsky VN, Tkachuk VA, Vyssokikh MY, Yaguzhinsky LS, Zorov DB (2009) An attempt to prevent senescence: A mitochondrial approach. Biochim Biophys Acta 1787, 437 461.

[16] Obukhova LA, Skulachev VP, Kolosova NG (2009) Mitochondria-targeted antioxidant SkQ1 inhibits agedependent involution of the thymus in normal and senescence-prone rats. Aging (Albany NY) 1, 389-401.

[17] Amstislavskaya TG, Maslova LN, Gladkikh DV, Belousova II, Stefanova NA, Kolosova NG (2010) Effects of the mitochondria-targeted antioxidant SkQ1 on sexually motivated behavior in male rats. Pharmacol Biochem Behav 96 , 211-216.

[18] Markovets AM, Fursova AZ, Kolosova NG (2011) Therapeutic action of the mitochondria-targeted antioxidant SkQ1 on retinopathy in OXYS rats linked with improvement of VEGF and PEDF gene expression. PLoS One 6, e21682.

[19] Saprunova VB, Lelekova MA, Kolosova NG, Bakeeva LE (2012) SkQ1 slows development of age-dependent destructive processes in retina and vascular layer of eyes of wistar and OXYS rats. Biochem (Mosc) 77, 648-658.

[20] Kolosova NG, Stefanova NA, Muraleva NA, Skulachev VP (2012) The mitochondria-targeted antioxidant SkQ1 but not $\mathrm{N}$-acetylcysteine reverses aging-related biomarkers in rats. Aging (Albany NY) 4, 686-694.

[21] Stefanova NA, Fursova AZh, Kolosova NG (2010) Behavioral effects induced by mitochondria-targeted antioxidant SkQ1 in Wistar and senescence-accelerated OXYS rats. J Alzheimers Dis 21, 479-491.

[22] Loskutova LV, Zelenkina LM (2002) Impairment of latent inhibition in OXYS rats with hereditary syndrome of premature aging. Zh Vyssh Nerv Deiat Im I P Pavlova 52, 366-370.

[23] Sergeeva S, Bagryanskaya E, Korbolina E, Kolosova N (2006) Development of behavioural dysfunctions in acceleratedsenescence OXYS rats is associated with early postnatal alterations in brain phosphate metabolism. Exp Gerontol 41 141-150.

[24] Kolosova NG, Stefanova NA, Sergeeva SV (2009) OXYS rats: A prospective model for evaluation of antioxidant availability in prevention and therapy of accelerated aging and age-related cognitive decline. In Handbook of Cognitive Aging: Causes, Processes and Effects. Gariépy Q, Ménard R, eds. Nova Science Publishers, New York, pp. 47-82.

[25] Agafonova IG, Rjtelnikov VN, Mishchenko NP, Kolosova NG (2010) Comparative study of the influence histochrome and mexidol on structural and functional characteristics of premature aging of the brain of rats OXYS by MRI. Bull Exp Biol Med 151, 380-384.

[26] Kolosova NG, Akulov AE, Stefanova NA, Moshkin MP, Savelov AA, Koptyug IV, Panov AV, Vavilin VA (2011) Effect of malate on the development of rotenone-induced brain changes in Wistar and OXYS rats: An MRI study. Dokl Biol Sci 437, 72-75.
[27] Beregovoy NA, Sorokina NS, Starostina MV, Kolosova NG (2011) Age-specific peculiarities of formation of long-term posttetanic potentiation in OXYS rats. Bull Exp Biol Med 151, 71-73.

[28] Kapay NA, Isaev NK, Stelmashook EV, Popova OV, Zorov DB, Skrebitsky VG, Skulachev VP (2011) In vivo injected mitochondria-targeted plastoquinone antioxidant SkQR1 prevents $\beta$-amyloid-induced decay of long-term potentiation in rat hippocampal slices. Biochem (Mosc) 76, 1367-1370.

[29] Shabalina IG, Kolosova NG, Grishanova AIu, Solov'ev VN, Salganik RI, Solov'eva NA (1995) Oxidative phosphorylation activity, F0F1-ATPase and level of liver mitochondrial cytochromes in rats with congenitally increased ability for free radical formation. Biokhimiia 60, 2045-2052.

[30] Kolosova NG, Aidagulova SV, Nepomnyashchikh GI, Shabalina IG, Shalbueva NI (2001) Dynamics of structural and functional changes in hepatocyte mitochondria of senescenceaccelerated OXYS rats. Bull Exp Biol Med 132, 814-819.

[31] Kolosova NG, Shcheglova TV, Sergeeva SV, Loskutova LV (2006) Long-term antioxidant supplementation attenuates oxidative stress markers and cognitive deficits in senescentaccelerated OXYS rats. Neurobiol Aging 27, 1289-1297.

[32] Handley SL, McBlane JW, Critchley MA, Njung'e K (1993) Multiple serotonin mechanisms in animal models of anxiety: Environmental, emotional and cognitive factors. Behav Brain Res 58, 203-210.

[33] File SE, Day S (1972) Effects of time of day and food deprivation on exploratory activity in the rat. Animal Behav 20, 758-762.

[34] Redrobe JP, Dumont Y, Herzog H, Quirion R (2003) Neuropeptide Y (NPY) Y2 receptors mediate behavior in two animal models of anxiety: Evidence from Y2 receptor knockout mice. Behav Brain Res 141, 251-255.

[35] Morris R (1984) Developments of a water-maze procedure for studying spatial learning in the rat. J Neurosci Methods 11, 47-60.

[36] Stefanova NA, Fursova AZh, Sarsenbaev KN, Kolosova NG (2011) Effects of Cistanche deserticola on behavior and signs of cataract and retinopathy in senescence-accelerated OXYS rats. J Ethnopharmacol 138, 624-632.

[37] Braidy N, Muñoz P, Palacios AG, Castellano-Gonzalez G, Inestrosa NC, Chung RS, Sachdev P, Guillemin GJ (2012) Recent rodent models for Alzheimer's disease: Clinical implications and basic research. J Neural Transm 119, 173-195.

[38] Savonenko AV, Melnikova T, Hiatt A, Li T, Worley PF, Troncoso JC, Wong PC, Price DL (2012) Alzheimer's therapeutics: Translation of preclinical science to clinical drug development. Neuropsychopharmacology 37, 261-277.

[39] Boguszewski P, Zagrodzka J (2002) Emotional changes related to age in rats - a behavioral analysis. Behav Brain Res 133, 323-332.

[40] Tanisawa K, Mikami E, Fuku N, Honda Y, Honda S, Ohsawa I, Ito M, Endo S, Ihara K, Ohno K, Kishimoto Y, Ishigami A, Maruyama N, Sawabe M, Iseki H, Okazaki Y, Hasegawa-Ishii S, Takei S, Shimada A, Hosokawa M, Mori M, Higuchi K, Takeda T, Higuchi M, Tanaka M (2013) Exome sequencing of senescence-accelerated mice (SAM) reveals deleterious mutations in degenerative disease-causing genes. BMC Genomic 14, 248.

[41] Andrews-Hanna JR, Snyder AZ, Vincent JL, Lustig C, Head D, Raichle ME, Buckner RL (2007) Disruption of large-scale brain systems in advanced aging. Neuron 56, 924-935.

[42] Chiu C, Miller MC, Caralopoulos IN, Worden MS, Brinker T, Gordon ZN, Johanson CE, Silverberg GD (2012) Temporal course of cerebrospinal fluid dynamics and amyloid 
accumulation in the aging rat brain from three to thirty months. Fluids Barriers CNS 9, 3.

[43] Mawuenyega KG, Sigurdson W, Ovod V, Munsell L, Kasten T, Morris JC, Yarasheski KE, Bateman RJ (2010) Decreased clearance of CNS beta-amyloid in Alzheimer's disease. Scienc 330, 1774

[44] Van Dam D, D'Hooge R, Staufenbiel M, Van Ginneken C, Van Meir F, De Deyn PP (2003) Age-dependent cognitive decline in the APP23 model precedes amyloid deposition. Eur J Neurosci 17, 388-396.

[45] Capetillo-Zarate E, Staufenbiel M, Abramowski D, Haass C, Escher A, Stadelmann C, Yamaguchi H, Wiestler OD, Thal DR (2006) Selective vulnerability of different types of commissural neurons for amyloid beta-protein-induced neurodegeneration in APP23 mice correlates with dendritic tree morphology. Brain 129(Pt 11), 2992-3005.

[46] Rijal Upadhaya A, Capetillo-Zarate E, Kosterin I, Abramowski D, Kumar S, Yamaguchi H, Walter J, Fändrich M, Staufenbiel M, Thal DR (2012) Dispersible amyloid $\beta$-protein oligomers, protofibrils, and fibrils represent diffusible but not soluble aggregates: Their role in neurodegeneration in amyloid precursor protein (APP) transgenic mice. Neurobiol Aging 33, 2641-2660.

[47] Kozhevnikova OS, Korbolina EE, Stefanova NA, Muraleva NA, Orlov YL, Kolosova NG (2013) Association of AMD-like retinopathy development with an Alzheimer's disease metabolic pathway in OXYS rats. Biogerontology, doi: 10.1007/s10522-013-9439-2 [PubMed PMID: 23859228]

[48] Lindner AB, Demarez A (2009) Protein aggregation as a paradigm of aging. Biochim Biophys Acta 1790, 980-996.

[49] Parihar MS, Brewer GJ (2010) Amyloid- $\beta$ as a modulator of synaptic plasticity. J Alzheimers Dis 22, 741-763.

[50] Swerdlow RH, Khan SM (2004) A "mitochondrial cascade hypothesis" for sporadic Alzheimer's disease. Med Hypotheses 63, 8-20.

[51] Swerdlow RH, Burns JM, Khan SM (2010) The Alzheimer's disease mitochondrial cascade hypothesis. J Alzheimers Dis 20, 265-279. 